\title{
Appraisals of psychotic experiences: an experimental investigation of symptomatic, remitted and non-need-for-care individuals
}

\author{
R. Underwood ${ }^{1}$, V. Kumari $^{2}$ and E. Peters ${ }^{2 *}$ \\ ${ }^{1}$ Department of Psychology, King's College London, Institute of Psychiatry, Psychology and Neuroscience, London, UK \\ ${ }^{2}$ National Institute for Health Research (NIHR) Biomedical Research Centre for Mental Health at South London and Maudsley NHS Foundation \\ Trust, London, UK
}

Background. Appraisals are suggested to play a determining role in the clinical outcome of psychotic experiences (PEs). We used experimental tasks that mimic PEs to investigate appraisals in individuals with PEs with and without a 'need-for-clinicalcare', and psychosis patients whose symptoms have remitted. We predicted that patients would appraise the tasks as threatening regardless of current symptom level, while non-clinical and control groups would appraise them as non-threatening.

Method. Appraisals following three anomalous experiences-inducing tasks [Telepath, Cards task, Virtual acoustic space paradigm (VASP)] were examined in 71 individuals: symptomatic $(n=18)$ and remitted $(n=16)$ psychosis patients; non-clinical group with PEs $(n=16)$; controls without PEs $(n=21)$.

Results. As predicted, symptomatic patients endorsed more threatening appraisals for all tasks than non-clinical and control groups, who did not differ from each other. However, remitted patients were less likely to endorse threatening appraisals of the Cards and Telepath than their symptomatic counterparts, although they did not differ in global ratings of how striking, threatening and distressing they found the tasks. Moreover, remitted participants endorsed more threatening appraisals of the Telepath and VASP than non-clinical participants, and of the VASP than controls. Remitted participants also rated all three tasks as globally more threatening than the non-clinical group and controls.

Conclusions. Clinical outcome may not necessarily be driven by the presence of symptoms, with threatening appraisals of PEs representing a key factor. The remitted group's intermediate appraisal scores imply that the relationship between appraisal and clinical outcome is not straightforward, and potential mediating factors need to be determined.

Received 16 June 2015; Revised 17 November 2015; Accepted 17 November 2015; First published online 25 January 2016

Key words: Anomalous experiences, appraisal, need-for-care, psychosis.

\section{Introduction}

Recent reviews and meta-analyses show a continuity of psychosis in the general population that includes healthy states (Van Os et al. 2009; Linscott \& Van Os, 2013). Cognitive models of psychosis suggest that appraisals can be distinguished or 'decoupled' from actual psychotic experiences (PEs), and play a key role in the transition to a clinical 'need-for-care' (Bentall et al. 2001; Garety et al. 2001, 2007; Morrison, 2001; Bentall et al. 2007; Howes \& Murray, 2014). According to Garety et al. (2001), maladaptive appraisals are those in which PEs are attributed to an external cause and seen as personally significant. These appraisals in

* Address for correspondence: E. Peters, National Institute for Health Research (NIHR) Biomedical Research Centre for Mental Health at South London and Maudsley NHS Foundation Trust, London SE5 8AF, UK.

(Email: emmanuelle.peters@kcl.ac.uk) turn may lead to symptom-associated distress, resulting in the individual needing treatment.

A minority of individuals report persistent PEs but have never sought or been in need of treatment (Linscott \& Van Os, 2013). These individuals form a valuable comparison group for clinical participants, as although their experiences tend to be less frequent, they are of equivalent phenomenology, but differ in outcome (Peters et al. in press). Using an in-depth interview [Appraisals of Anomalous Experiences Interview (AANEX); Brett et al. 2007], we previously found that non-need-for-care individuals normalize their experiences as psychologically explainable phenomena, or integrate them within a spiritual or paranormal framework (Brett et al. 2007; Lovatt et al. 2010), which in turn is predictive of less distress (Brett et al. 2014).

These studies also demonstrated that externally attributed experiences are not necessarily maladaptive, since non-need-for-care participants also attribute their PEs to external, albeit benevolent, causes such as spiritual guidance (Brett et al. 2007). Rather, group differences

This is an Open Access article, distributed under the terms of the Creative Commons Attribution licence (http://creativecommons.org/licenses/by/4.0/), which permits unrestricted re-use, distribution, and reproduction in any medium, provided the original work is properly cited. 
concerned attributions of danger, emotional valence and agency, with clinical participants typically viewing their experiences as caused by other people who wish them harm. Ultimately, the core of maladaptive appraisals contributing to a need-for-care relate to threat. Cognitively, non-need-for-care individuals may have decoupled threatening appraisals from their PEs.

Recently, these differences in appraisals between those with and without a need-for-care have been replicated using anomalous experience-inducing tasks (Linney \& Peters, 2007; Taylor et al. 2013; Ward et al. 2014). Employing tasks that mimic PEs provides each participant with an identical experience, enabling variation in appraisals to be disentangled from variation in the phenomenology and content of PEs.

To date, studies have compared non-clinical with clinical participants with ongoing PEs, but not with clinical participants whose symptoms have remitted. Cognitive models of psychosis would predict that clinical individuals would retain a threat-based appraisal style even when their symptoms have remitted, since appraisal style can be disentangled from PEs themselves, with a range of potential risk factors contributing to threatening appraisals independently of the presence of PEs (Garety \& Freeman, 2013). Indeed, recent evidence showed that patients displayed a personalizing bias (i.e. blaming other people for a negative event) regardless of whether their paranoia symptoms were acute or remitted (Berry et al. 2014).

The present study sought to replicate and extend previous findings, first by comparing appraisals of experimentally induced anomalous experiences across four groups: symptomatic and remitted psychosis patients, those with PEs but without a need-for-care, and controls without PEs. Second, a new anomalous experience-inducing task, the 'Telepath', was administered in addition to the Cards and Virtual acoustic space paradigm (VASP) tasks (previously used in Ward et al. 2014). It was predicted that patients, regardless of symptom level, would appraise the tasks as more threatening than those without a need-for-care and controls, who would not differ from each other. It was also predicted that symptomatic and remitted patients would exhibit equivalent appraisal scores.

\section{Method}

The study was approved by Dulwich Research Ethics Committee (13/LO/0390).

\section{Participants}

\section{Clinical groups}

The 18 symptomatic and 16 remitted participants were pa tients with a psychosis spectrum disorder [International
Classification of Diseases (ICD)-10 diagnoses F20-F39]. To distinguish symptomatic and remitted groups, symptomatic patients all had a current score $\geqslant 3$ (hallucination occurring at least weekly/delusional belief with high conviction) on one or more items of the Scale for the Assessment of Positive Symptoms (SAPS; Andreasen, 1984), while remitted patients all had previously experienced positive psychotic symptoms, but in the last month scored $\leqslant 2$ (hallucination occurring at most monthly/simple delusions that are questioned) on any SAPS item. Patients were recruited from in-patient wards,out-patient recovery services, service-user led organizations and a psychological therapies service (Psychological Interventions Clinic for out-patients with Psychosis; PICuP) research register, all in the South London and Maudsley NHS Foundation Trust.

\section{Non-clinical group}

A total of 16 individuals displaying PEs but without a need-for-care (i.e. had never received a diagnosis, or been in need of mental health services for their experiences) were recruited. Individuals were screened for PEs on the Unusual Experiences Screening tool (see below), and only those with a score $\geqslant 3$ on one or more SAPS items (to match the symptomatic group), in the absence of drug use and in clear consciousness, and whose experiences started more than 5 years previously (to avoid prodromal individuals), participated. Anyone scoring 2 ('unmet need') on the 'psychological distress' (in relation to PEs) and 'self-care' dimensions of the Camberwell Assessment of Need Short Appraisal Schedule (CANSAS; Slade et al. 1999) were excluded. Non-clinical participants were recruited from specialist sources using a sampling strategy developed in previous studies (Heriot-Maitland et al. 2012; Ward et al. 2014). None had ever had contact with secondary care mental health services, but two had received treatment for depression from their general practitioner in the past.

\section{Control group}

A total of 21 controls scoring within 1 standard deviation of the population mean (15) or lower on the unusual experiences subscale of the Oxford-Liverpool Inventory of Feelings and Experiences (O-LIFE; Mason et al. 1995) were recruited. Online advertisements were distributed via a circular email list internal to King's College London, local online forums and the 'Experimatch' online research register. None had ever had contact with primary or secondary care services for mental health problems.

\section{All groups}

All participants were required to have normal or corrected vision and hearing. 


\section{Exclusion criteria}

Exclusion criteria were: insufficient command of English; neurological history, head injury or epilepsy; primary substance dependence; estimated intelligence quotient (IQ) $<70$ [estimated from Wechsler Test of Adult Reading (WTAR); Wechsler, 2001]. A history of common mental disorders was not an exclusion criterion for any group. Participants were excluded if they had previously seen the anomalous exper ience-inducing tasks.

The sample demographic and clinical characteristics are presented in Tables 1 and 2, including group differences (all of which were in line with previous findings in these groups; Peters et al. in press).

\section{Measures}

SAPS (Andreasen, 1984) and Scale for the Assessment of Negative Symptoms (SANS; Andreasen, 1983)

SAPS and SANS are interviews assessing positive/negative symptoms over the last month, rated on a six-point scale (0-5), and have shown good reliability and internal consistency (Andreasen \& Grove, 1986; Mance \& Haas, 1994).

Unusual Experiences Screening Questionnaire [UESQ; derived from the Appraisals of Anomalous Experiences Interview (Brett et al. 2007) and the Psychosis Screening Questionnaire (Bebbington E Nayani, 1995)]

The two screening measures were merged to avoid repetition of items. The UESQ assesses the presence of positive and first-rank psychotic symptoms within the last month and in the absence of drug use and in clear consciousness.

\section{CANSAS (Slade et al. 1999)}

The CANSAS was used to determine any unmet needs relating to underlying mental illness in the non-clinical group. Items 1-4 (covering basic selfcare) and 9 ('psychological distress': 'have you recently felt very sad or low in relation to PEs?') were used. Scores for each item are: $0=$ no problem; $1=$ met need; 2 = unmet need; and $9=$ not known.

\section{O-LIFE (Mason et al. 1995)}

The O-LIFE measures psychosis-proneness. The 30-item unusual experiences subscale (assessing mild forms of anomalous experiences such as having vivid daydreams) was used to screen the control group. The O-LIFE has shown good validity and reliability (Mason \& Claridge, 2006).
AANEX - short form (Lovatt et al. 2010)

The short-form AANEX-Inventory consists of 17 items covering five factors: 'meaning-reference' (e.g. ideas of reference); 'paranormal-hallucinatory' (e.g. visual or somatic hallucinations); 'cognitive-attention' (e.g. thought block); 'dissociative-perceptual' (e.g. depersonalization); and 'first-rank symptoms' (e.g. hearing voices). There are three items per factor, except 'meaning-reference' and 'first-rank symptoms' factors which have four items each. Each item is rated for the lifetime presence of the experience, and within the last month, as 'not present' (1), 'unclear' (2) or 'present' (3). Factor scores are obtained by summing individual item scores (range of scores for each factor: 3-9, except 'meaningreference' and 'first-rank symptoms' where the range is 4-12). Total scores range from 17 to 51. The AANEX has demonstrated good reliability and construct validity (Brett et al. 2007).

21-Item Depression Anxiety and Stress Scales (DASS-21; Lovibond E Lovibond, 1995)

The DASS-21 is a 21-item self-report questionnaire assessing depression, anxiety and stress over the previous week, with seven items in each subscale. Each item is scored from 0 (did not apply to me at all) to 3 (applied to me very much or most of the time). Scores for each subscale range between 0 and 21, and total score between 0 and 61. The DASS-21 has demonstrated good validity for measuring the dimensions of depression, anxiety and stress (Henry \& Crawford, 2005).

\section{The WTAR (Wechsler, 2001)}

The WTAR is a measure of pre-morbid IQ consisting of 50 irregularly spelled words that the participant is asked to pronounce sequentially. There is evidence that the WTAR is robust in the context of low effort (Whitney et al. 2010).

\section{Anomalous experiences analogue tasks ${ }^{1} \dagger$}

Cards task (http://sprott.physics.wisc.edu/pickover/esp2. html; Linney $\mathcal{E}$ Peters, 2007)

This task was used as an 'analogue' of thought interference symptoms. This card trick gives the impression that a computer has been able to read the participant's mind. Participants are shown six playing cards (face cards only) on a computer, and are asked to memorize one. They are then informed that their card will be selected and removed. They are subsequently shown five different cards for $3 \mathrm{~s}$. This trick relies on the fact

t The note appears after the main text. 
Table 1. Sample characteristics and statistical differences between the symptomatic, remitted, non-clinical and control groups

\begin{tabular}{|c|c|c|c|c|c|c|}
\hline & Characteristics & C-S $(n=18)$ & C-R $(n=16)$ & $\mathrm{NC}(n=16)$ & $\begin{array}{l}\text { Controls } \\
(n=21)\end{array}$ & Significance tests \\
\hline \multirow[t]{2}{*}{ Gender, $n$} & Male & 13 & 8 & 5 & 7 & $\chi^{2}{ }_{3}=7.826, p=0.050(V=0.33)$ \\
\hline & Female & 5 & 8 & 11 & 14 & C-S: male $>$ female \\
\hline Mean age, years (S.D.) & & $42.56(12.03)$ & $43.75(11.95)$ & $52.5(9.25)$ & $30.05(10.32)$ & $F_{3,67}=13.35, p<0.001\left(\eta_{\mathrm{p}}^{2}=0.37\right)^{\mathrm{p} * * *, \mathrm{i}^{* *}}$ \\
\hline \multirow[t]{2}{*}{ Ethnicity, $n$} & Whites & 7 & 11 & 14 & 15 & $\chi^{2}{ }_{6}=12.76, p=0.047(V=0.30)$ \\
\hline & Non-whites & 11 & 5 & 2 & 6 & C-S: non-white $>$ white \\
\hline \multirow[t]{2}{*}{ Employment, $n$} & $\begin{array}{l}\text { Employed/in } \\
\text { education }\end{array}$ & 4 & 7 & 15 & 17 & $\begin{array}{l}\chi_{3}^{2}=23.11, p<0.001(V=0.57) \\
\text { NC and controls: employed > unemployed; }\end{array}$ \\
\hline & Not employed & 14 & 9 & 1 & 4 & C-S: unemployed > employed \\
\hline \multicolumn{2}{|c|}{ Mean time in education, years (s.D.) ${ }^{\mathrm{a}}$} & $15.12(3.76)$ & $15.07(3.73)$ & $22.5(8.00)$ & $18.95(7.05)$ & $F_{3,64}=5.46, p=0.002\left(\eta_{\mathrm{p}}^{2}=0.20\right)^{\mathrm{d}^{* *}, \mathrm{e}^{* *}}$ \\
\hline \multirow[t]{2}{*}{$\begin{array}{l}\text { Highest level of } \\
\text { education, } n\end{array}$} & $\begin{array}{l}\text { University } \\
\text { education }\end{array}$ & 7 & 5 & 11 & 15 & $\begin{array}{l}\chi^{2}{ }_{3}=17.31, p=0.001(V=0.49) \\
\text { NC: } \text { university }>\text { no university }\end{array}$ \\
\hline & $\begin{array}{l}\text { No university } \\
\text { education }\end{array}$ & 11 & 11 & 5 & 6 & \\
\hline Mean WTAR (S.D.) & $\begin{array}{l}\text { Predicted } \\
\text { full-scale IQ }\end{array}$ & $102.33(10.19)$ & $103.31(8.25)$ & $109.31(3.50)$ & $111(4.74)$ & $F_{3,67}=6.69, p=0.001\left(\eta_{\mathrm{p}}^{2}=0.23\right)^{\mathrm{d}^{*}, \mathrm{~g}^{* *}, \mathrm{~h}^{*}}$ \\
\hline \multirow[t]{3}{*}{ Religious affiliation, $n$} & Traditional & 15 & 7 & 7 & 5 & $\chi^{2}{ }_{6}=18.25, p=0.004,(V=0.36)$ \\
\hline & Other/spiritual & 1 & 2 & 2 & 1 & C-S: traditional $>$ no affiliation \\
\hline & None & 2 & 7 & 7 & 16 & \\
\hline \multirow[t]{3}{*}{ Mean DASS-21 (S.D.) } & Depression & $6.56(4.78)$ & $7.25(6.56)$ & $0.69(1.08)$ & $1.57(1.63)$ & $F_{3,67}=11.84, p<0.001\left(\eta_{\mathrm{p}}^{2}=0.35\right)^{\mathrm{i} * *,} \mathrm{j}^{* * *}, \mathrm{k}^{* * *}, \mathrm{l}^{* * *}$ \\
\hline & Anxiety & $5.72(5.30)$ & $6.75(5.94)$ & $0.94(1.18)$ & $0.90(1.37)$ & $F_{3,67}=10.57, p<0.001\left(\eta_{\mathrm{p}}^{2}=0.32\right)^{\mathrm{i} * *,} \mathrm{j}^{* *}, \mathrm{k}^{* * *}, \mathrm{l}^{* *}$ \\
\hline & Stress & $7.67(6.16)$ & $9.31(6.03)$ & $2.69(2.09)$ & $3.14(3.51)$ & $F_{3,67}=8.32, p<0.001\left(\eta_{\mathrm{p}}^{2}=0.27\right)^{\mathrm{i}^{*}, \mathrm{j}^{*}, \mathrm{k}^{* *}, \mathrm{l}^{* *}}$ \\
\hline \multirow[t]{3}{*}{ Parental occupation, $n$} & $\begin{array}{l}\text { Professional/ } \\
\text { intermediate }\end{array}$ & 13 & 10 & 12 & 16 & $\chi^{2}{ }_{3}=2.17, p=0.54(V=0.18)$ \\
\hline & Other & 5 & 6 & 4 & 4 & \\
\hline & Missing value & 0 & 0 & 0 & 1 & \\
\hline \multirow[t]{2}{*}{ Children, $n$} & Yes & 3 & 6 & 11 & 2 & $\chi^{2}{ }_{3}=17.24, p=0.001(V=0.49)$ \\
\hline & No & 15 & 10 & 5 & 19 & NC: children $>$ no children \\
\hline \multirow[t]{4}{*}{ Diagnosis by ICD-10 } & & Schizophrenia = $14(78 \%)$ & Schizophrenia $=6(37.5 \%)$ & - & - & Schizophrenia: C-S > C-R \\
\hline & & Schizo-affective = $2(11 \%)$ & Schizo-affective $=1(6.25 \%)$ & & & F30-F39: C-R > C-S \\
\hline & & Psychosis NOS $=0$ & Psychosis NOS $=1(6.25 \%)$ & & & \\
\hline & & $\mathrm{F} 30-\mathrm{F} 39=2(11 \%)$ & $\mathrm{F} 30-\mathrm{F} 39=8(50 \%)$ & & & \\
\hline
\end{tabular}




\begin{tabular}{|c|c|c|c|c|c|}
\hline $\begin{array}{l}\text { Antipsychotic } \\
\text { medication and } \\
\text { dosages }\end{array}$ & $\begin{array}{l}\text { Medicated }=17(94.4 \%) \\
\text { None }=1(5.6 \%) \\
\text { Typical }=5.6 \% \\
\text { Atypical }=66.7 \% \\
\text { Clozapine }=16.7 \% \\
\text { More than } 1=11.1 \% \\
\text { Median }=50 \% \text { maximum } \\
\text { daily recommended dose } \\
(\text { range }=17-100 \%)^{b}\end{array}$ & $\begin{array}{l}\text { Medicated }=10(62.5 \%) \\
\text { None }=6(37.5 \%) \\
\text { Typical }=0 \% \\
\text { Atypical }=37.5 \% \\
\text { Clozapine }=12.5 \% \\
\text { More than } 1=0 \% \\
\text { Median }=39 \% \text { maximum daily } \\
\text { recommended dose (range }=5- \\
100 \%)^{c}\end{array}$ & - & - & $\begin{array}{l}\chi^{2}{ }_{1}=3.70, p=0.054(V=0.33) \\
\text { On medication: } C-S>C-R\end{array}$ \\
\hline $\begin{array}{l}\text { Mean time since } \\
\text { onset, years (S.D.) }\end{array}$ & 20.47 (13.15) & $19.20(14.16)$ & 38.07 (15.44) & - & $F_{2,43}=8.02, p=0.001\left(\eta_{\mathrm{p}}^{2}=0.27\right)^{\mathrm{d} * *,} \mathrm{e}^{* *}$ \\
\hline
\end{tabular}

C-S, Symptomatic, C-R, remitted, NC, non-clinical; S.D., standard deviation; WTAR, Wechsler Test of Adult Reading; IQ, intelligence quotient; DASS-21, 21-item Depression Anxiety and Stress Scales; ICD, International Classification of Diseases; NOS, not otherwise specified.

${ }^{a}$ One value was missing for C-S, and two for C-R.

${ }^{\mathrm{b}}$ Six participants had missing data for dosage.

${ }^{\mathrm{c}}$ One participant had missing data for dosage.

${ }^{\mathrm{d}} \mathrm{NC} v$. C-S.

${ }^{\mathrm{e}} \mathrm{NC} v$. C-R.

${ }^{\mathrm{f}} \mathrm{NC} v$. controls.

g Controls $v$. C-S.

${ }^{\mathrm{h}}$ Controls $v$. C-R.

${ }^{\mathrm{i}} \mathrm{C}-\mathrm{S} v$. controls.

${ }^{\mathrm{j}} \mathrm{C}-\mathrm{S} v$. NC.

${ }^{\mathrm{k}} \mathrm{C}-\mathrm{R} v$. controls.

${ }^{1} \mathrm{C}-\mathrm{R} v$. NC.

${ }^{*} p<0.05,{ }^{* *} p<0.01,{ }^{* * *} p<0.001$ (Tukey's least significant difference test). 
Table 2. Summary of clinical measure scores by group and statistical differences between symptomatic, remitted and non-clinical groups ${ }^{\mathrm{a}}$

\begin{tabular}{|c|c|c|c|c|}
\hline & & & & $\mathrm{C}-\mathrm{S} v . \mathrm{NC}$ \\
\hline & C-S $(n=18)$ & C-R $(n=16)$ & $\mathrm{NC}(n=16)$ & $\mathrm{NC} v . \mathrm{CR}$ \\
\hline SAPS hallucinations & $3.72(1.71)$ & $0.44(0.81)$ & $2.75(1.53)$ & $\begin{array}{l}U=206.5, p=0.030(d=0.43) \\
U=33, p<0.001 \quad(d=0.74)\end{array}$ \\
\hline SAPS delusions & $3.67(1.24)$ & $0.69(0.95)$ & $2.81(0.75)$ & $\begin{array}{l}U=227.5, p=0.003(d=0.58) \\
U=11, p<0.001(d=0.91)\end{array}$ \\
\hline SAPS thought disorder & $1.0(1.41)$ & 0 & $0.19(0.54)$ & $\begin{array}{l}U=186.5, p=0.144(d=0.30) \\
U=112, p=0.564(d=0.12)\end{array}$ \\
\hline SAPS bizarre behaviour & $0.78(1.11)$ & $0.13(0.50)$ & $0.06(0.25)$ & $\begin{array}{l}U=193.5, p=0.088(d=0.34) \\
U=128.5, p=1.00(d=0.00)\end{array}$ \\
\hline SAPS inappropriate affect & $0.17(0.71)$ & 0 & 0 & $\begin{array}{l}U=152, p=0.798(d=0.05) \\
U=128, p=1.00(d=0.00)\end{array}$ \\
\hline SANS affective flattening & $1.17(1.25)$ & $0.31(0.87)$ & 0 & $\begin{array}{l}U=224, p=0.005(d=0.55) \\
U=144, p=0.564(d=0.13)\end{array}$ \\
\hline SANS alogia & $1.28(1.27)$ & $0.06(0.25)$ & 0 & $\begin{array}{l}U=224, p=0.005(d=0.55) \\
U=136, p=0.780(d=0.06)\end{array}$ \\
\hline SANS avolition & $2.56(1.69)$ & $1.44(1.71)$ & 0 & $\begin{array}{l}U=256, p<0.001(d=0.78) \\
U=192, p=0.015(d=0.50) \mathrm{b}\end{array}$ \\
\hline SANS anhedonia & $0.76(2.05)$ & $1.00(1.51)$ & 0 & $\begin{array}{l}U=216, p=0.012(d=0.50) \\
U=176, p=0.073(d=0.38)\end{array}$ \\
\hline SANS attention & $2.61(1.69)$ & $2.61(1.69)$ & $1.63(1.46)$ & $\begin{array}{l}U=194.5, p=0.081(d=0.35) \\
U=145, p=0.539(d=0.13)\end{array}$ \\
\hline $\begin{array}{l}\text { AANEX total - lifetime } \\
\text { experiences }\end{array}$ & $33.94(9.31)$ & $32.75(8.78)$ & $38.13(3.95)$ & $\begin{array}{l}U=115.5, p=0.330(d=0.20) \\
U=89, p=0.149(d=0.30)\end{array}$ \\
\hline $\begin{array}{l}\text { AANEX total - current } \\
\text { experiences }\end{array}$ & $31.28(7.93)$ & $21.44(3.97)$ & $35.06(4.36)$ & $\begin{array}{l}U=95.5, p=0.095(d=0.34) \\
U=3.5, p<0.001(d=0.97)\end{array}$ \\
\hline Total AANEX score & $63.22(16.00)$ & $52.25(10.68)$ & $70.19(7.11)$ & $\begin{array}{l}U=109.5, p=0.237(d=0.24) \\
U=19, p<0.001(d=0.85)\end{array}$ \\
\hline $\begin{array}{l}\text { AANEX - meaning-reference - } \\
\text { current }\end{array}$ & $6.83(2.23)$ & $4.88(1.26)$ & $10.44(1.97)$ & $\begin{array}{l}U=35.5, p<0.001(d=0.75) \\
U=5, p<0.001(d=0.96)\end{array}$ \\
\hline $\begin{array}{l}\text { AANEX - 'paranormal- } \\
\text { hallucinatory' - current }\end{array}$ & $4.94(1.63)$ & $3.19(0.54)$ & $6.50(1.41)$ & $\begin{array}{l}U=74.5, p=0.015(d=0.48) \\
U=3, p<0.001(d=0.98)\end{array}$ \\
\hline $\begin{array}{l}\text { AANEX - 'cognitive-attention' - } \\
\text { current }\end{array}$ & $4.78(2.16)$ & $3.75(1.61)$ & $3.19(0.54)$ & $\begin{array}{l}U=205, p=0.036(d=0.42) \\
U=139, p=0.696(d=0.09)\end{array}$ \\
\hline $\begin{array}{l}\text { AANEX - 'dissociative- } \\
\text { perceptual' - current }\end{array}$ & $4.39(1.58)$ & $3.31(0.70)$ & $4.38(1.78)$ & $\begin{array}{l}U=148, p=0.905(d=0.03) \\
U=82.5, p=0.86(d=0.36)\end{array}$ \\
\hline $\begin{array}{l}\text { AANEX - first rank symptoms - } \\
\text { current }\end{array}$ & $10.44(2.55)$ & $5.88(1.41)$ & $10.06(1.53)$ & $\begin{array}{l}U=157.5, p=0.646(d=0.09) \\
U=7.5, p<0.001(d=0.94)\end{array}$ \\
\hline
\end{tabular}

Data are given as mean (standard deviation).

C-S, Symptomatic; C-R, remitted; NC, non-clinical; SAPS, Scale for the Assessment of Positive Symptoms (Andreasen, 1984); SANS, Scale for the Assessment of Negative Symptoms (Andreasen, 1983); AANEX, Appraisals of Anomalous Experiences Interview (Brett et al. 2007).

${ }^{a}$ All scores for SAPS and SANS items are global scores.

${ }^{\mathrm{b}} \mathrm{C}-\mathrm{R}$ significantly higher than NC.

that people only scan for the card they have chosen and do not notice that all the cards have been replaced with similar but different face cards. This process was repeated five times.

Telepath phone application (http://richardwiseman. wordpress.com/video-audio/can-you-figure-out-the-secretof-telepath/)
This 'mindreading' task was also an analogue of thought interference, using a smartphone application, presented via webcam on a computer screen. Four numbers (1-4) are presented to the participant who is required to mentally choose one number. Following the phone being placed face down (shaking the phone in the process), the participant is asked to reveal their choice to the experimenter. Unknown to the 
Table 3. Threatening and non-threatening appraisal styles in the three experimental tasks

\begin{tabular}{|c|c|c|c|}
\hline & Cards task & Telepath task & VASP \\
\hline \multicolumn{4}{|l|}{ Non-threatening appraisals } \\
\hline External - normalizing & 'It is just a simple card puzzle' & $\begin{array}{l}\text { 'It is just a simple number } \\
\text { puzzle' }\end{array}$ & $\begin{array}{l}\text { 'It is part of the study and } \\
\text { involves a pre-recorded } \\
\text { voice' }\end{array}$ \\
\hline Internal - normalizing & \multicolumn{3}{|c|}{$\begin{array}{l}\text { 'It is to do with natural extrasensory perception (ESP)/psychic or paranormal abilities' } \\
\text { 'There is a rational explanation involving basic attention/perception' }\end{array}$} \\
\hline \multicolumn{4}{|l|}{ Threatening appraisals } \\
\hline External - personalizing & $\begin{array}{l}\text { 'It is not the computer which } \\
\text { guessed; there is someone } \\
\text { involved in this' }\end{array}$ & $\begin{array}{l}\text { 'It was not just about the phone; } \\
\text { there is someone behind the } \\
\text { scenes involved' }\end{array}$ & $\begin{array}{l}\text { 'Someone was speaking to } \\
\text { me' }^{\text {' }}\end{array}$ \\
\hline $\begin{array}{l}\text { External - } \\
\text { non-personalizing }\end{array}$ & \multicolumn{2}{|c|}{ 'It works because the system is able to read people's minds' } & $\begin{array}{l}\text { 'There was a spirit or some } \\
\text { kind of entity in the room' }\end{array}$ \\
\hline External - intentionalizing & \multicolumn{3}{|c|}{ 'It was done on purpose to trick me, or make me look stupid' } \\
\hline External - generalizing & \multicolumn{3}{|c|}{ 'It is a trick that is part of a bigger conspiracy' } \\
\hline $\begin{array}{l}\text { Internal - } \\
\text { non-normalizing }\end{array}$ & \multicolumn{3}{|c|}{ 'This means that something is wrong with me' } \\
\hline
\end{tabular}

VASP, Virtual acoustic space paradigm.

participant, shaking the phone activates an animation, cycling through each number consecutively, with each transition signalled by a sparkle sound every $8 \mathrm{~s}$, enabling the experimenter to keep track. When the phone is lifted up by the experimenter the animation freezes and 'magically' reveals the chosen number. This process is repeated six times (see Appendix 1 for further description).

\section{VASP (Wightman \& Kistler, 1989)}

This task was designed to be an 'analogue' of auditory hallucinations or 'loud thoughts' (Ward et al. 2014). The VASP allows sounds to be perceived as externally located through acoustic manipulation via computer software, despite presentation via headphones (for a detailed description of the acoustic manipulation process, see Ward et al. 2014). Participants are informed that the task assesses the effects of distraction on performance, as they are asked to complete a distractor task (determining the presence of objects in fuzzy images) while listening to the headphones. The participant's name is recorded beforehand, along with neutral commands ('listen up', 'pay attention', 'concentrate'), heard as if originating from 'outside the head'. These recordings are then played back at random intervals over a soundtrack of white noise (heard 'inside the head').

\section{Assessment of appraisals}

Following each task, spontaneous explanations for the anomalous experiences were elicited to determine if the manipulation had been guessed correctly. Subseq uently, participants completed a computerized rating scale (0-10) asking them to rate their conviction in a number of predetermined possible explanations. The explanations were taken from Ward et al. (2014), reflecting the most relevant appraisal styles ascertained in previous studies, namely normalizing, personalizing, intentionalizing, generalizing and externalizing/internalizing (Brett et al. 2007; Linney \& Peters, 2007). The seven explanations used and their corresponding appraisal styles, categorized into 'threatening' and 'non-threatening', are summarized in Table 3. A further three visual analogue scales were used to assess globally how striking, distressing and threatening the participants found the tasks.

\section{Apparatus}

All tasks were presented on a laptop. Speech for the VASP was recorded through the laptop soundcard using the software programme Cool Edit Pro (Syntrillium Software Corporation, 2003), recording at $16000 \mathrm{~Hz} 16$ bit mono. The computer audio output level was set at 28/50, with the white noise attenuated to $-14 \mathrm{Db}$ and the voice files to $-10 \mathrm{Db}$ within the VASP's Graphical User Interface (GUI). All tasks were programmed in Visual Basic.NET and were operated via a GUI.

\section{Procedure}

Presentation of the three tasks was pseudo-randomized to control for order effects. The remaining measures were presented in such a way as to limit the effects of fatigue on performance, e.g. more challenging or lengthy measures were presented nearer the beginning of the session. Upon completion of the 
Table 4. Non-parametric correlations between appraisal scores (separated into threatening and non-threatening) across tasks in the combined groups

Cards threatening appraisals

\begin{tabular}{|c|c|c|c|}
\hline Cards threatening appraisals & - & $0.70^{* * *}$ & $0.59^{* * *}$ \\
\hline Telepath threatening appraisals & & - & $0.61^{* * *}$ \\
\hline \multirow[t]{2}{*}{ VASP threatening appraisals } & & & - \\
\hline & $\begin{array}{l}\text { Cards non-threatening } \\
\text { appraisals }\end{array}$ & $\begin{array}{l}\text { Telepath non-threatening } \\
\text { appraisals }\end{array}$ & $\begin{array}{l}\text { VASP non-threatening } \\
\text { appraisals }\end{array}$ \\
\hline $\begin{array}{l}\text { Cards non-threatening } \\
\text { appraisals }\end{array}$ & - & $0.39^{* *}$ & $0.40^{* *}$ \\
\hline $\begin{array}{l}\text { Telepath non-threatening } \\
\text { appraisals }\end{array}$ & & - & $0.34^{* *}$ \\
\hline $\begin{array}{l}\text { VASP non-threatening } \\
\text { appraisals }\end{array}$ & & & - \\
\hline
\end{tabular}

VASP, Virtual acoustic space paradigm.

** $p<0.01,{ }^{* * *} p<0.001$.

study, participants were debriefed and compensated for their time and travel.

\section{Data analysis}

Data analysis was carried out using SPSS for Windows (version 22, 2013). The $\alpha$-level of significance (twotailed) was set at $p<0.05$ unless indicated otherwise. Appraisals were split into 'non-threatening' and 'threatening' for analysis (see Table 3). Appraisal ratings from participants who guessed the true nature of the tasks were included, on the grounds that they could be considered as non-threatening appraisals, that happened to be correct. We previously carried out sensitivity analyses in a larger sample to examine whether group differences in appraisals of the same tasks were affected by the inclusion or exclusion of correct guesses (Peters et al. 2015), and found that observed group differences remained the same. Appraisal data were not normally distributed, and were analysed using non-parametric statistics. Main effect of group was analysed using a Kruskal-Wallis $H$ test, followed by Mann-Whitney $U$ tests for individual group comparisons. Effect size estimates were calculated using Cliff's delta (Cliff, 1993), a robust, non-parametric equivalent to Cohen's $d$ (Hess \& Kromrey, 2004). The thresholds of magnitude for Cliff's delta are: $d<0.147$ 'negligible', $d<0.33$ 'small', $d<0.474$ 'medium', otherwise 'large' (Romano et al. 2006).

\section{Results}

Threatening and non-threatening appraisals correlated highly across all three tasks (Table 4), showing good reliability for the tasks to elicit similar responses within each participant.

\section{Cards task}

In all, one symptomatic (5.55\%), three remitted (18.75\%), four non-clinical (25\%) and 10 control participants $(47.62 \%)$ guessed the nature of the Cards task correctly. Group was a significant predictor of correct guesses $\left(\chi^{2}=9.60, p<0.05\right)$, with standardized residuals indicating that controls were more likely than symptomatic and remitted participants to guess the task.

There was a main effect of group for threatening appraihigher scores than non-clinical participants and controls, while the latter two groups did not differ. Contrary to predictions, the remitted group had lower (at near-significant level, with a medium effect size) threatening appraisal scores than the symptomatic group, and did not differ from the non-clinical or control groups. There were no group differences for non-threatening appraisals.

There were main effects of group for global ratings of striking, distress and threat (Table 5). Symptomatic participants found the task more striking and distressing than non-clinical participants, but not controls, and ticipants. The remitted group found the task more striking (at trend-level significance) and distressing than non-clinical participants, and more threatening than both non-clinical and control groups. Symptomatic and remitted participants did not differ across all global ratings, nor did non-clinical and control participants.

\section{Telepath task}

Only one non-clinical (6.25\%) and one control participant $(4.76 \%)$ guessed the trick behind the Telepath task correctly. Group was not a significant predictor of correct guesses. There was a significant effect of sals (Table 5). As predicted, symptomatic participants had more threatening than did controls and non-clinical par- 
Table 5. Appraisal scores and global ratings of how striking, threatening and distressing the three experimental tasks were in symptomatic, remitted, non-clinical and control groups, and statistical comparisons (with effect sizes)

\begin{tabular}{|c|c|c|c|c|c|c|c|c|c|c|c|}
\hline & C-S $(n=18)$ & C-R $(n=16)$ & NC $(n=16)$ & $\begin{array}{l}\text { Controls } \\
(n=21)\end{array}$ & $\begin{array}{l}\text { Significant } \\
\text { group effects }\end{array}$ & $\mathrm{C}-\mathrm{S} v \cdot \mathrm{NC}$ & $\mathrm{C}-\mathrm{R} v \cdot \mathrm{NC}$ & $\begin{array}{l}\mathrm{NC} v . \\
\text { controls }\end{array}$ & C-S v. C-R & $\begin{array}{l}\text { C-S } v \text {. } \\
\text { controls }\end{array}$ & $\begin{array}{l}\text { C-R } v \text {. } \\
\text { controls }\end{array}$ \\
\hline \multicolumn{12}{|c|}{ Threatening appraisals } \\
\hline Cards & $2.57(2.14)$ & $0.96(1.39)$ & $0.45(0.75)$ & $0.65(0.88)$ & $H=13.11, p=0.004$ & $\begin{array}{c}U=214 \\
p=0.002 \\
(d=0.49)\end{array}$ & $\begin{array}{c}U=171.5 \\
p=0.102 \\
(d=0.34)\end{array}$ & $\begin{array}{l}U=156 \\
p=0.728 \\
(d=0.07)\end{array}$ & $\begin{array}{l}U=87 \\
p=0.050 \\
(d=0.39)\end{array}$ & $\begin{array}{r}U=267.5 \\
p=0.004 \\
(d=0.42)\end{array}$ & $\begin{array}{c}U=201, \\
p=0.323 \\
(d=0.20)\end{array}$ \\
\hline Telepath & $2.33(1.65)$ & $1.33(1.35)$ & $0.36(0.56)$ & $0.71(0.94)$ & $H=18.12, p<0.001$ & $\begin{array}{c}U=234.5 \\
p<0.001 \\
(d=0.63)\end{array}$ & $\begin{array}{l}U=184, p \\
=0.035 \\
(d=0.44)\end{array}$ & $\begin{array}{r}U=138.5 \\
p=0.370 \\
(d=0.18)\end{array}$ & $\begin{array}{c}U=89, p= \\
0.059,(d \\
=0.38)\end{array}$ & $\begin{array}{l}U=283, p \\
=0.001 \\
(d=0.50)\end{array}$ & $\begin{array}{r}U=212.5 \\
p=0.175 \\
(d=0.26)\end{array}$ \\
\hline VASP & $2.30(1.68)$ & $1.58(1.50)$ & $0.49(0.78)$ & $0.88(1.27)$ & $H=16.95, p=0.001$ & $\begin{array}{c}U=229.5 \\
p<0.001 \\
(d=0.59)\end{array}$ & $\begin{array}{r}U=192.5 \\
p=0.014 \\
(d=0.50)\end{array}$ & $\begin{array}{r}U=148.5 \\
p=0.554 \\
(d=0.12)\end{array}$ & $\begin{array}{c}U=105 p \\
=0.187 \\
(d=0.27)\end{array}$ & $\begin{array}{c}U=277 \\
p=0.003 \\
(d=0.47)\end{array}$ & $\begin{array}{r}U=232.5 \\
p=0.047 \\
(d=0.38)\end{array}$ \\
\hline \multicolumn{12}{|c|}{ Non-threatening appraisals } \\
\hline Cards & $3.94(1.49)$ & $4.25(1.53)$ & $4.52(2.33)$ & $4.81(1.38)$ & $H=3.75, p=0.290$ & - & - & - & - & - & - \\
\hline Telepath & $4.56(2.30)$ & $4.13(1.44)$ & $3.92(2.09)$ & $4.40(1.38)$ & $H=1.07, p=0.785$ & - & - & - & - & - & - \\
\hline VASP & $5.39(1.53)$ & $4.81(1.76)$ & $6.04(1.28)$ & $6.10(0.84)$ & $H=7.86, p=0.049$ & $\begin{array}{r}U=106.5 \\
p=0.198 \\
(d=0.26)\end{array}$ & $\begin{array}{c}U=71.5 \\
p=0.032 \\
(d=0.44)\end{array}$ & $\begin{array}{r}U=140.5 \\
p=0.404 \\
(d=0.16)\end{array}$ & $\begin{array}{c}U=116.5 \\
p=0.347 \\
(d=0.19)\end{array}$ & $\begin{array}{r}U=135.5 \\
p=0.133 \\
(d=0.28)\end{array}$ & $\begin{array}{l}U=84, \\
p=0.018, \\
(d=0.56)\end{array}$ \\
\hline \multicolumn{12}{|c|}{ Global striking } \\
\hline Cards & $6.00(3.33)$ & $4.88(3.28)$ & $2.63(2.66)$ & $4.29(3.33)$ & $H=8.79, p=0.032$ & $\begin{array}{c}U=224 \\
p=0.004 \\
(d=0.55)\end{array}$ & $\begin{array}{c}U=180 \\
p=0.051 \\
(d=0.41)\end{array}$ & $\begin{array}{r}U=117.5 \\
p=0.123 \\
(d=0.30)\end{array}$ & $\begin{array}{c}U=114.5 \\
p=0.313 \\
(d=0.20)\end{array}$ & $\begin{array}{r}U=242.5 \\
p=0.133 \\
(d=0.28)\end{array}$ & $\begin{array}{r}U=184.5 \\
p=0.617 \\
(d=0.10)\end{array}$ \\
\hline Telepath & $6.11(2.72)$ & $5.25(3.09)$ & $4.06(3.12)$ & $3.81(3.25)$ & $H=6.43, p=0.093$ & - & - & - & - & - & - \\
\hline VASP & $5.83(2.73)$ & $5.63(2.66)$ & $3.63(3.20)$ & $4.10(2.15)$ & $H=7.02, p=0.071$ & - & - & - & - & - & - \\
\hline \multicolumn{12}{|c|}{ Global threat } \\
\hline Cards & $2.56(3.24)$ & $1.19(1.52)$ & $0(0)$ & $0.19(0.51)$ & $H=19.27, p<0.001$ & $\begin{array}{r}U=202.5 \\
p=0.005 \\
(d=0.41)\end{array}$ & $\begin{array}{r}U=234.5 \\
p=0.015 \\
(d=0.40)\end{array}$ & $\begin{array}{l}U=144 \\
p=0.476 \\
(d=0.21)\end{array}$ & $\begin{array}{l}U=120 \\
p=0.422 \\
(d=0.17)\end{array}$ & $\begin{array}{l}U=277 \\
p=0.012 \\
(d=0.47)\end{array}$ & $\begin{array}{l}U=192 \\
p=0.040 \\
(d=0.50)\end{array}$ \\
\hline Telepath & $1.56(2.92)$ & $1.88(2.42)$ & $0.06(0.25)$ & $0.24(0.77)$ & $H=10.12, p=0.006$ & $\begin{array}{l}U=185 \\
p=0.164 \\
(d=0.28)\end{array}$ & $\begin{array}{l}U=187 \\
p=0.026 \\
(d=0.46)\end{array}$ & $\begin{array}{r}U=161.5 \\
p=0.844 \\
(d=0.04)\end{array}$ & $\begin{array}{l}U=165 \\
p=0.484 \\
(d=0.15)\end{array}$ & $\begin{array}{l}U=236 \\
p=0.192 \\
(d=0.25)\end{array}$ & $\begin{array}{r}U=238.5 \\
p=0.029 \\
(d=0.42)\end{array}$ \\
\hline VASP & $2.28(3.16)$ & $3.50(3.12)$ & $0.81(1.60)$ & $1.24(1.79)$ & $H=7.90, p=0.048$ & $\begin{array}{l}U=179 \\
p=0.237 \\
(d=0.24)\end{array}$ & $\begin{array}{l}U=191 \\
p=0.017 \\
(d=0.49)\end{array}$ & $\begin{array}{r}U=141.5 \\
p=0.421 \\
(d=0.16)\end{array}$ & $\begin{array}{c}U=178.5 \\
p=0.237 \\
(d=0.24)\end{array}$ & $\begin{array}{c}U=211.5 \\
p=0.530 \\
(d=0.12)\end{array}$ & $\begin{array}{c}U=236, p \\
=0.037 \\
(d=0.40)\end{array}$ \\
\hline
\end{tabular}


group for threatening appraisals (Table 5). As predicted, symptomatic participants had higher scores than did non-clinical participants and controls, as did the remitted group compared with the non-clinical group, but not controls. Also as expected, the control and non-clinical groups did not differ. Unexpectedly, remitted participants had lower scores (at trend level) than symptomatic participants, with a medium effect size. There were no group differences for nonthreatening appraisals.

There was a main effect of group for global ratings of threat and distress (Table 5), but not striking. The symptomatic group found it more distressing than controls (and at trend level) than non-clinical participants. The remitted group found the Telepath more threatening than the non-clinical group and controls. Remitted and symptomatic participants did not differ on global ratings, nor did controls and non-clinical participants.

\section{VASP}

In all, 12 symptomatic (66.7\%), 12 remitted (75\%), 15 non-clinical (93.75\%) and 21 controls (100\%) guessed the nature of the VASP correctly. Group was not a significant predictor of correct guesses. There was a main effect of group for threatening appraisals (Table 5). As predicted, both symptomatic and remitted participants had higher scores than non-clinical participants and controls, and did not differ from each other; nor did the non-clinical and control groups. There was a main effect for non-threatening appraisals, with remitted participants having lower scores than non-clinical participants and controls. There were no other group differences for non-threatening appraisals.

There was a main effect for global ratings of threat, but not striking or distress (Table 5). The remitted group found the VASP more threatening than the nonclinical group and controls. Symptomatic and remitted participants did not differ on global ratings, nor did controls and non-clinical participants.

\section{Discussion}

\section{Summary of findings}

As predicted, clinical participants with ongoing symptoms displayed greater threatening appraisals across all three anomalous experience-inducing tasks, compared with non-need-for-care individuals with PEs and controls, who did not differ from each other. Remitted participants endorsed more threatening appraisals of Telepath and VASP tasks than the non-clinical group, and of the VASP than controls. Symptomatic and remitted participants also generally found the tasks a more globally distressing and threatening experience than 


\section{5}

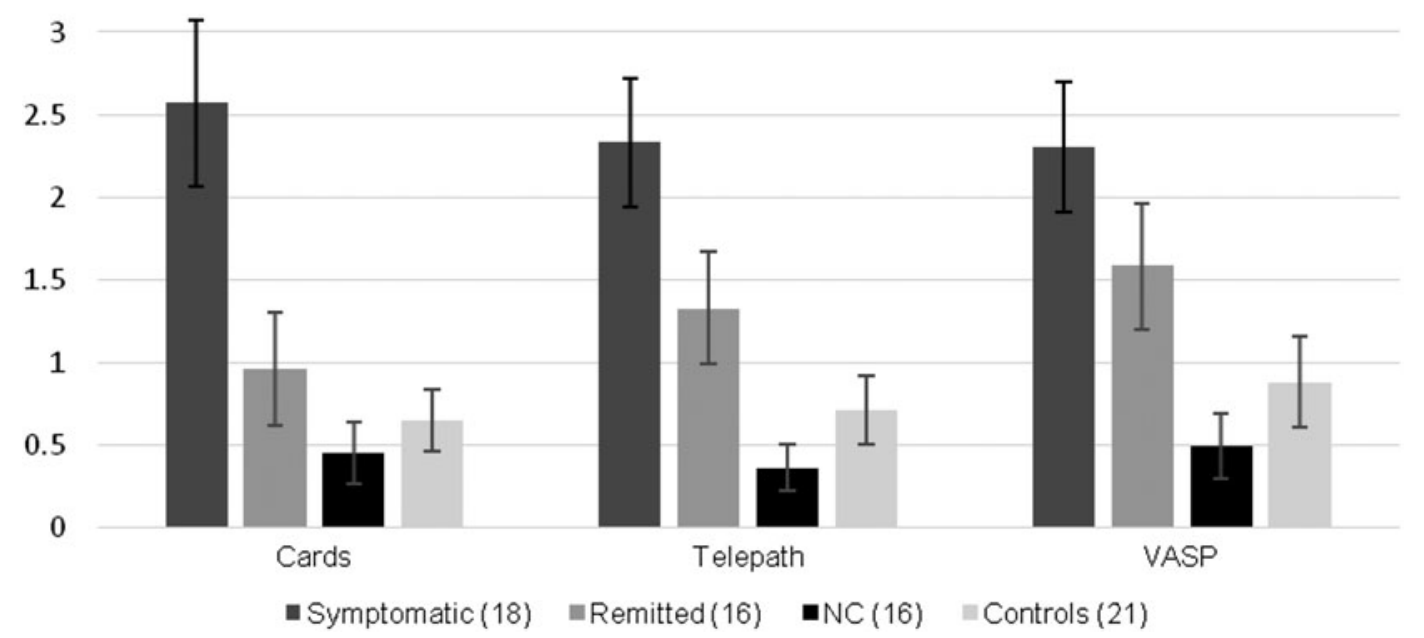

Fig. 1. Differences in threatening appraisals scores for each task in symptomatic, remitted, non-clinical (NC) and control groups. Values are means, with standard errors represented by vertical bars. VASP, Virtual acoustic space paradigm.

controls and non-clinical participants. Furthermore, the two clinical groups did not differ in any global ratings; neither did non-clinical and control participants. Overall these results are consistent with previous findings that clinical status can be differentiated by cognitive appraisals of anomalous experiences. They also bring validity to a novel task, the Telepath, an analogue of thought interference similar to the Cards task. The Telepath produced higher effect sizes than the Cards task when comparing symptomatic participants and non-clinical participants, and fewer participants across groups guessed the manipulation.

Contrary to predictions, however, symptomatic and remitted participants differed from one another in terms of threatening appraisals for two out of the three tasks, albeit at trend level and with medium, rather than large, effect sizes. The remitted and control groups also showed statistically indistinguishable threatening appraisals for two of the three tasks. As can be seen clearly in Fig. 1, ratings for the remitted group were intermediate between the symptomatic group and controls for each task, with non-clinical participants having the lowest ratings.

\section{Implications for the cognitive model of psychosis}

In cognitive models of psychosis (Bentall et al. 2001, 2007; Garety et al. 2001, 2007; Morrison, 2001; Howes \& Murray, 2014), threatening appraisals are not considered specific to psychosis, but rather a transdiagnostic risk factor representing cognitive biases and disturbed affect that develop independently of PEs, and are thus trait-dependent (Freeman \& Garety, 2003). Although causality cannot be inferred, the findings in the remitted group indicate a potential dampening of threatening appraisals as symptoms remit in clinical individuals, implying that threatening appraisals may be, in part, secondary to the presence of PEs, and thus statedependent. However, non-clinical participants had significantly more current PEs than did remitted individuals, despite having the lowest threatening appraisal scores of any group. Hence, it is possible that appraisals are both state- and trait-dependent. It may be that clinical individuals exhibit an already heightened threatening appraisal style that becomes exacerbated as symptoms become more frequent and intense. Those without a need-for-care, on the other hand, have managed to decouple threatening appraisals from PEs entirely.

Another explanation may relate to PEs and appraisal styles sharing a dynamic relationship. Studies using experience sampling methods show subtle fluctuations in the relationship between negative affect, stress and symptom intensity (Delespaul \& Van Os, 2002; Peters et al. 2012; Kramer et al. 2014). Successfully decoupling threatening appraisals from PEs may in turn affect their content, frequency and intensity. Potentially, non-need-for-care individuals' experiences have never reached the same intensity and frequency of those in clinical groups, further facilitating a decoupling of threatening appraisals from their experiences. This could be due to increased striatal dopamine in clinical individuals, producing greater aberrant salience (Kapur, 2003), and thus increased PEs (Howes \& Murray, 2014). Interestingly, healthy voice-hearers have been found to show intact dopamine regulation (Howes et al. 2013). This suggests, alternatively, that dopamine dysregulation may not drive presence of PEs per se, but secondary factors, such as intrusiveness, or even threatening appraisals. 
It is also possible that specific types of experiences play a role in eliciting threatening appraisals; for instance, clinical individuals hear voices with greater unpleasant content than healthy voice-hearers (Daalman et al. 2011). Given that the VASP produced the largest differences between clinical and non-clinical groups, it may be that auditory hallucinations are a greater predictor of heightened threat appraisal.

There were significant demographic differences between the groups. Estimated IQ in the non-clinical group was higher than in both clinical groups, for example. Such differences have been found consistently across previous studies (Brett et al. 2007; Lovatt et al. 2010; Ward et al. 2014), and may be significant determinants of a need-for-care (Peters et al. in press). This would imply that they represent real group differences rather than sampling error, whether these differences are a consequence of group status (e.g. distress, low mood), or developmental risk factors (e.g. low IQ, socioeconomic deprivation). Ideally these differences would be controlled for in the analysis. However, there is a compelling argument that statistical methods used to control for group differences, such as analysis of covariance, should only be used to control for random variance, and it is therefore invalid to control for preexisting, non-random group differences common to psychopathology research (Miller \& Chapman, 2001).

Nevertheless, such group differences are likely to be relevant to the ability of non-need-for-care individuals to appraise PEs as non-threatening. There is limited evidence, for example, that exposure to trauma is equivalent between those with and without a need-for-care, but that the specific types and impact of trauma differ significantly (Lovatt et al. 2010). Similarly, a recent study showed that the jumping-to-conclusions bias, which potentially underlies threat appraisal, is less pronounced in those without a need-for-care (Lim et al. 2012). Future studies should attempt to test whether the relationship between PEs and threatening appraisals is mediated by trauma, IQ, socio-economic status and other environmental factors, to determine which may have a protective effect $v$. those that increase risk for distress.

\section{Limitations}

The remitted and symptomatic groups differed demographically and clinically, with the former group having fewer previous admissions, despite similar onset and duration of illness. The remitted group were also less likely to be diagnosed with schizophrenia, which carries a worse long-term prognosis than affective disorders (Jobe \& Harrow, 2005). The differences in severity of illness between the two patient groups may have contributed to the unexpected differences in threatening appraisals.
The symptomatic group had more severe positive symptoms generally than the non-clinical group on the SAPS, suggesting that these groups may not be wholly comparable. However there were fewer differences on the AANEX, a measure more suited for interviewing non-clinical populations than the SAPS. Moreover, the minimum inclusion criteria for the nonclinical group required that PEs occur at least weekly.

Both clinical groups exhibited heightened depression, anxiety and stress scores compared with the nonclinical and control groups, as well as lower IQ scores. Affective symptoms may result in PEs being perceived as more subjectively intrusive, and personally significant (Krabbendam \& Os, 2005), and a personalizing bias for negative events has been linked to poor IQ (Berry et al. 2014).

Another limitation was the high percentage of participants who guessed the manipulation behind the tasks correctly, particularly in the VASP task. This may have been affected by the number of repetitions, as each task had been altered to be presented multiple times (see Appendix 2). Despite this, there were no significant differences between groups for percentage of correct guesses, apart from the Cards task, where controls were significantly more likely to guess the manipulation. Crucially, each task produced a similar pattern of results, regardless of the percentage of correct guesses, suggesting that correct guesses did not invalidate the findings.

The number of group comparisons being conducted across the three tasks may have inflated type I error. Multiple Mann-Whitney $U$ tests were employed as there are no satisfactory non-parametric equivalents of the post-hoc Tukey test for individual comparisons. Bonferroni or Dunn-Sidak adjustment is considered an overcautious method that can miss meaningful group differences (Ruxton \& Beauchamp, 2008). Coupled with the small sample sizes, it was felt that the risk of type II error outweighed that of type I. Furthermore, effect sizes provide a better indication of real group differences (Kirk, 2003; Cumming, 2013), which in this study were moderate to large overall for the significant and nearsignificant findings, and negligible for the non-clinical and control group comparisons.

A further limitation is that some of the remitted $(n=10$; $63 \%)$ and symptomatic $(n=8 ; 44 \%)$ individuals had received cognitive-behavioural therapy for psychosis (CBTp), which targets threatening appraisals (Fowler et al. 1995). Those who had received CBTp in the remitted group (but not the symptomatic group) had lower threatening appraisal scores than those who had not $(U=11.5$, $p=0.042, d=0.62)$, although only on the Telepath. The high number in the remitted group with prior exposure to CBTp may have contributed to this group's intermediate threatening appraisal scores relative to other groups. The small sample sizes make it difficult to make a proper 
inference, but the effects of CBTp on appraisals in the clinical groups cannot be discounted. Finally, sampling bias in the way each group was recruited cannot be excluded as a source of variance.

\section{Conclusions}

Overall, this study has provided further evidence that how PEs are interpreted, rather than their presence, may be key to clinical status. Non-clinical participants with PEs were characterized by the lack of threatening appraisals of anomalous perceptual experiences on all tasks, similarly to controls, and unlike psychosis patients.

The novel and unexpected finding was that clinical participants whose symptoms had remitted, a heretofore untested population with regards to appraisals of PEs, exhibited threatening appraisals of the tasks that placed them in between their symptomatic counterparts and controls, implying that threatening appraisals and distressing symptoms may partly diminish in tandem. Nevertheless, those without a need-for-care appraised anomalous experiences as non-threatening despite ongoing PEs, suggesting that they had found a way to decouple threatening appraisals from the presence of PEs. Further research should seek to uncover the potential mediating factors in this relationship.

\section{Acknowledgements}

The authors thank the Medical Research Council and the Institute of Psychiatry, Psychology and Neuroscience, King's College London for providing the grant funding this work.

\section{Declaration of Interest}

None.

\section{Note}

${ }^{1}$ All three anomalous experience-inducing tasks described were adapted to facilitate future use in a neuroimaging environment, which included repeated exposures and the inclusion of a control condition. The tasks in their adapted forms were piloted and found to have retained their effectiveness. See Appendix 2 for details. Appraisal score data presented herein were in response to these adapted tasks, but for the sake of succinctness the control conditions, which are not relevant to this study, have been omitted from task descriptions.

\section{References}

Andreasen NC (1983). Scale for the Assessment of Negative Symptoms. University of Iowa: Iowa City, IA.

Andreasen NC (1984). Scale for the Assessment of Positive Symptoms. University of Iowa: Iowa City, IA.
Andreasen NC, Grove WM (1986). Evaluation of positive and negative symptoms in schizophrenia. Psychiatrie et Psychobiologie 2, 108-121.

Bebbington PE, Nayani T (1995). The Psychosis Screening Questionnaire. International Journal of Methods in Psychiatric Research 5, 11-19.

Bentall RP, Corcoran R, Howard R, Blackwood N, Kinderman P (2001). Persecutory delusions: a review and theoretical integration. Clinical Psychology Review 21, 1143-1192.

Bentall RP, Fernyhough C, Morrison AP, Lewis S, Corcoran R (2007). Prospects for a cognitive-developmental account of psychotic experiences. British Journal of Clinical Psychology 46, 155-173.

Berry K, Bucci S, Kinderman P, Emsley R, Corcoran R (2014). An investigation of attributional style, theory of mind and executive functioning in acute paranoia and remission. Psychiatry Research 226, 84-90.

Brett C, Heriot-Maitland C, McGuire P, Peters E (2014). Predictors of distress associated with psychotic-like anomalous experiences in clinical and non-clinical populations. British Journal of Clinical Psychology 53, 213-227.

Brett CM, Peters EP, Johns LC, Tabraham P, Valmaggia LR, Mcguire P (2007). Appraisals of Anomalous Experiences Interview (AANEX): a multidimensional measure of psychological responses to anomalies associated with psychosis. British Journal of Psychiatry 51, s23-s30.

Cliff N (1993). Dominance statistics: ordinal analyses to answer ordinal questions. Psychological Bulletin 114, 494-509.

Cumming G (2013). Understanding the New Statistics: Effect Sizes, Confidence Intervals, and Meta-Analysis. Routledge: New York.

Daalman K, Boks MP, Diederen KM, De Weijer AD, Blom JD, Kahn RS, Sommer IE (2011). The same or different? A phenomenological comparison of auditory verbal hallucinations in healthy and psychotic individuals. Journal of Clinical Psychiatry 72, 320-325.

Delespaul P, Van Os J (2002). Determinants of occurrence and recovery from hallucinations in daily life. Social Psychiatry and Psychiatric Epidemiology 37, 97-104.

Fowler D, Garety P, Kuipers L (1995). Cognitive Behaviour Therapy for Psychosis: Theory and Practice. Wiley: Chichester.

Freeman D, Garety PA (2003). Connecting neurosis and psychosis: the direct influence of emotion on delusions and hallucinations. Behaviour Research and Therapy 41, 923-947.

Garety P, Freeman D (2013). The past and future of delusions research: from the inexplicable to the treatable. British Journal of Psychiatry 203, 327-333.

Garety PA, Bebbington P, Fowler D, Freeman D, Kuipers E (2007). Implications for neurobiological research of cognitive models of psychosis: a theoretical paper. Psychological Medicine 37, 1377-1391.

Garety PA, Kuipers E, Fowler D, Freeman D, Bebbington PE (2001). A cognitive model of the positive symptoms of psychosis. Psychological Medicine 31, 189-195.

Henry JD, Crawford JR (2005). The short-form version of the Depression Anxiety Stress Scales (DASS-21): construct validity and normative data in a large non-clinical sample. British Journal of Clinical Psychology 44, 227-239. 
Heriot-Maitland C, Knight M, Peters E (2012). A qualitative comparison of psychotic-like phenomena in clinical and non-clinical populations. British Journal of Clinical Psychology 51, 37-53.

Hess MR, Kromrey JD (2004). Robust confidence intervals for effect sizes: a comparative study of Cohen's $d$ and Cliff's delta under non-normality and heterogeneous variances. Annual Meeting of the American Educational Research Association, 12-16 April 2004 (http://citeseerx.ist.psu.edu/ viewdoc/download?doi=10.1.1.487. 8299\&rep=rep1\&type=pdf). Accessed December 2015.

Howes OD, Murray RM (2014). Schizophrenia: an integrated sociodevelopmental-cognitive model. Lancet 383, 1677-1687.

Howes OD, Shotbolt P, Bloomfield M, Daalman K, Demjaha A, Diederen KM, Ibrahim K, Kim E, McGuire P, Kahn RS (2013). Dopaminergic function in the psychosis spectrum: an $\left[{ }^{18} \mathrm{~F}\right]$-DOPA imaging study in healthy individuals with auditory hallucinations. Schizophrenia Bulletin 39, 807-814.

Jobe TH, Harrow M (2005). Long-term outcome of patients with schizophrenia: a review. Canadian Journal of Psychiatry 50, 892-900.

Kapur S (2003). Psychosis as a state of aberrant salience: a framework linking biology, phenomenology, and pharmacology in schizophrenia. American Journal of Psychiatry 160, 13-23.

Kirk RE (2003). The Importance of Effect Magnitude. Handbook of Research Methods in Experimental Psychology. Blackwell Publishing Ltd: Oxford.

Krabbendam L, Os J (2005). Affective processes in the onset and persistence of psychosis. European Archives of Psychiatry and Clinical Neuroscience 255, 185-189.

Kramer I, Simons CJ, Wigman JT, Collip D, Jacobs N, Derom C, Thiery E, Van Os J, Myin-Germeys I, Wichers M (2014). Time-lagged moment-to-moment interplay between negative affect and paranoia: new insights in the affective pathway to psychosis. Schizophrenia Bulletin 40, 278-286.

Lim MH, Gleeson JF, Jackson HJ (2012). The jumping-to-conclusions bias in new religious movements. Journal of Nervous and Mental Disease 200, 868-875.

Linney YM, Peters ER (2007). The psychological processes underlying symptoms of thought interference in psychosis. Behaviour Research and Therapy 45, 2726-2741.

Linscott RJ, Van Os J (2013). An updated and conservative systematic review and meta-analysis of epidemiological evidence on psychotic experiences in children and adults: on the pathway from proneness to persistence to dimensional expression across mental disorders. Psychological Medicine 43, 1133-1149.

Lovatt A, Mason O, Brett C, Peters E (2010). Psychotic-like experiences, appraisals, and trauma. Journal of Nervous Mental Disorders 198, 813-819.

Lovibond S, Lovibond P (1995). Manual for the Depression Anxiety Stress Scales. The Psychology Foundation of Australia. Inc.: Sydney.

Mance RM, Haas GL (1994). A multisite investigation of the reliability of the Scale for the Assessment of Negative Symptoms. American Journal of Psychiatry 151, 1453-1462.
Mason O, Claridge G (2006). The Oxford-Liverpool Inventory of Feelings and Experiences (O-LIFE): further description and extended norms. Schizophrenia Research 82, 203-211.

Mason O, Claridge G, Jackson M (1995). New scales for the assessment of schizotypy. Personality and Individual Differences 18, 7-13.

Miller GA, Chapman JP (2001). Misunderstanding analysis of covariance. Journal of Abnormal Psychology 110, 40-48.

Morrison AP (2001). The interpretation of intrusions in psychosis: an integrative cognitive approach to hallucinations and delusions. Behavioural Cognitive Psychotherapy 29, 257-276.

Peters E, Lataster T, Greenwood K, Kuipers E, Scott J, Williams S, Garety P, Myin-Germeys I (2012). Appraisals, psychotic symptoms and affect in daily life. Psychological Medicine 42, 1013-1023.

Peters E, Ward T, Jackson M, Morgan C, Charalambides M, McGuire P, Woodruff P, Jacobsen P, Chadwick P, Garety PA (in press). Clinical, socio-demographic, and psychological characteristics in individuals with persistent psychotic experiences with and without a "need-for-care". World Psychiatry.

Peters E, Ward T, Jackson M, Morgan C, Woodruff P, McGuire P, Garety P (2015). Exploring psychotic experiences in non-need for care populations: findings from the unique study (Unusual Experiences Enquiry Study). Schizophrenia Bulletin 41, S186.

Romano J, Kromrey JD, Coraggio J, Skowronek J (2006). Appropriate statistics for ordinal level data: should we really be using $t$-test and Cohen's $d$ for evaluating group differences on the NSSE and other surveys? Annual Meeting of the Florida Association of Institutional Research, 14-17 October 2006 (http://www.scribd.com/doc/45715000/ Appropriate-Statistics-for-Ordinal-Level-Data\#scribd). Accessed December 2015.

Ruxton GD, Beauchamp G (2008). Time for some a priori thinking about post hoc testing. Behavioral Ecology 19, 690693.

Slade M, Loftus L, Phelan M, Thornicroft G, Wykes T (1999). The Camberwell Assessment of Need. Gaskell: London. Syntrillium Software Corporation (2003). Cool Edit Pro. Syntrillium Software Corporation: Phoenix, AZ.

Taylor HE, Parker S, Mansell W, Morrison AP (2013). Effects of appraisals of anomalous experience on distress in people at risk of psychosis. Behavioural and Cognitive Psychotherapy 41, 24-33.

Van Os J, Linscott RJ, Myin-Germeys I, Delespaul P, Krabbendam L (2009). A systematic review and meta-analysis of the psychosis continuum: evidence for a psychosis proneness-persistence-impairment model of psychotic disorder. Psychological Medicine 39, 179-195.

Ward T, Gaynor K, Hunter M, Woodruff P, Garety P, Peters E (2014). Appraisals and responses to experimental symptom analogues in clinical and nonclinical individuals with psychotic experiences. Schizophrenia Bulletin 40, 845-855.

Wechsler D (2001). Wechsler Test of Adult Reading: WTAR. Psychological Corporation: San Antonio, TX.

Whitney KA, Shepard PH, Mariner J, Mossbarger B, Herman SM (2010). Validity of the Wechsler Test of Adult 
Reading (WTAR): effort considered in a clinical sample of US military veterans. Applied Neuropsychology 17, 196-204.

Wightman FL, Kistler DJ (1989). Headphone simulation of free-field listening. I: stimulus synthesis. Journal of the Acoustical Society of America 85, 858-867.

\section{Appendix 1 \\ Telepath task description}

See Fig. 2 for an illustration of the Telepath task. While the phone was face down, the experimenter waited the requisite amount of time for the desired number to appear on the phone's screen ( $8 \mathrm{~s}$ for ' 1 ', $16 \mathrm{~s}$ for ' 2 ', $24 \mathrm{~s}$ for ' 3 ', and $32 \mathrm{~s}$ for ' 4 '). During this time, the experimenter distracted the participant by asking them to focus mentally on their number, rehearse it, and then attempt to transmit it to the device onscreen. As a consequence of the differing lengths of time for each number, the experimental condition did not have a set length.

\section{Appendix 2}

\section{Adaptation of the three anomalous experience-inducing tasks}

All three tasks were adapted, so that their adapted forms would lend themselves to usage within a neuroimaging environment. Adapting the tasks involved taking into account the design and presentational constraints imposed by the magnetic resonance imaging scanner, such as stimuli having to be presented on a computer screen, participant responses being non-verbal, and each experimental condition matching with a control condition (not reported in this study) identical in all respects apart from the variable of interest.

Central among these constraints was the number of trials per task, as neuroimaging typically demands multiple presentations of a stimulus in order to yield reliable activation in the region(s) of interest. The most suitable solution (minimum of five trials) was found in a previous study investigating auditory verbal hallucinations in psychotic patients.

Piloting was conducted with five controls and five non-clinical individuals. Overall, the control conditions and multiple trials for each task were not perceived as confusing, and did not contribute to awareness of the manipulation. Additionally, verbal feedback from participants also indicated that the voice samples heard during the VASP were perceived as externally located, even if they knew that it was a recording, thus validating its design.
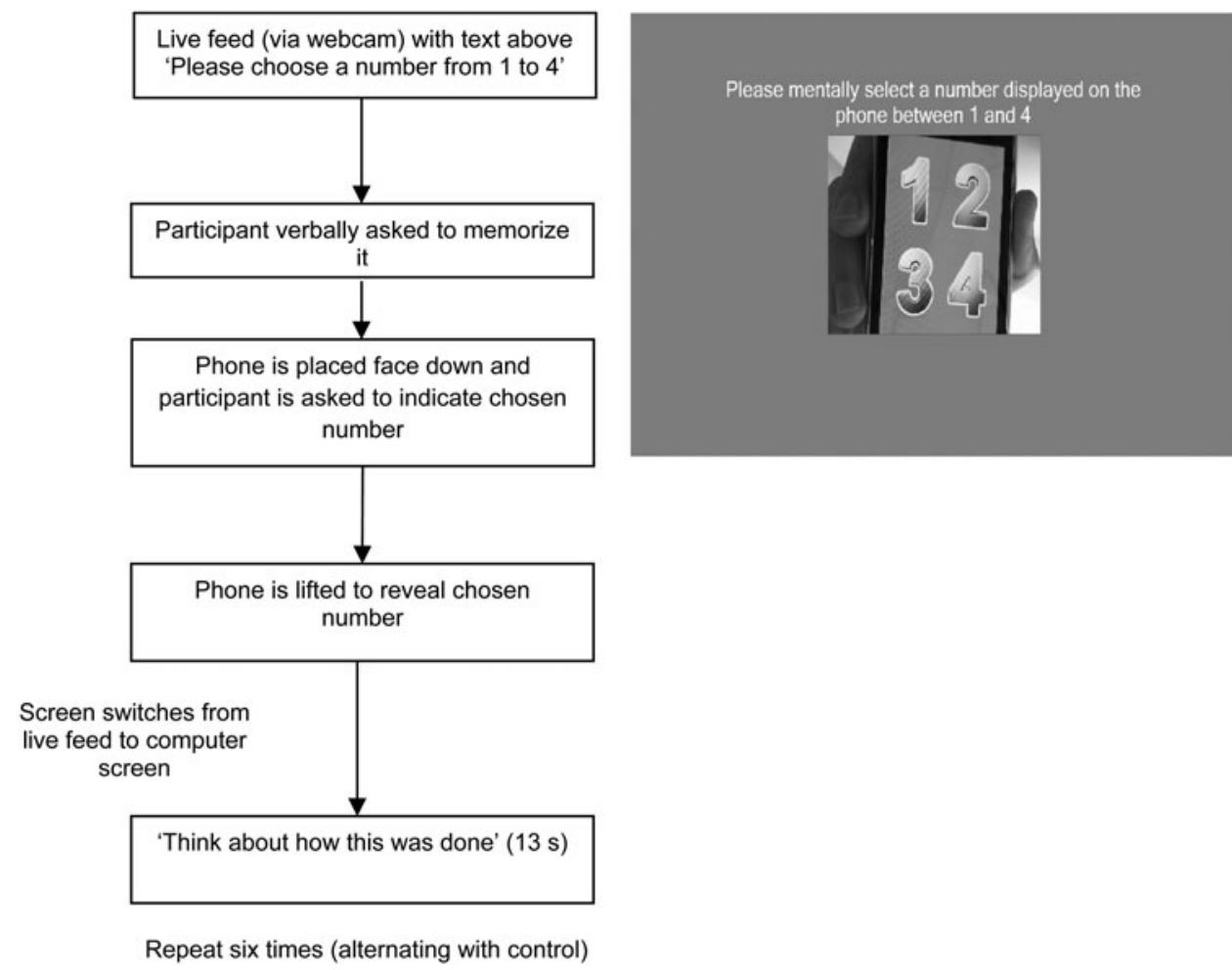

Fig. 2. Telepath experimental condition 